\title{
Mixture toxicity of zinc oxide nanoparticle and chemicals with different mode of action upon Vibrio fischeri
}

Fen Chen ${ }^{1,2+}$, Ligui Wu ${ }^{2,3+}$, Xiaoyu Xiao ${ }^{2}$, Lingling Rong ${ }^{2}, \mathrm{Mi} \mathrm{Li}^{2,4^{*}}$ and Xiaoming Zou ${ }^{1,2^{*}}$

\begin{abstract}
Background: Zinc oxide nanoparticle $(n \mathrm{ZnO})$ and chemicals with different mode of action $(\mathrm{MOA}$, i.e., narcotic and reactive) were frequently detected in the Yangtze River. Organisms are typically exposed to mixtures of $n Z n O$ and other chemicals rather than individual $n Z n O$. Toxicity of $n \mathrm{ZnO}$ is caused by the dissolution of $\mathrm{Zn}^{2+}$, which has been proved in the field of single toxicity. However, it is still unclear whether the released $\mathrm{Zn}^{2+}$ plays a critical role in the $n \mathrm{ZnO}$ toxicity of $n \mathrm{ZnO}$-chemicals mixtures. In the present study, the binary mixture toxicity of $n \mathrm{ZnO} / \mathrm{Zn}^{2+}$ and chemicals with different MOA was investigated in acute $(15 \mathrm{~min})$ and chronic $(12 \mathrm{~h})$ toxicity test upon Vibrio fischeri $(\mathrm{V}$. fischeri). The joint effects of $n \mathrm{ZnO}$ and tested chemicals were explored. Moreover, two classic models, concentration addition (CA) and independent action (IA) were applied to predict the toxicity of mixtures.

Results: The difference of toxicity unit (TU) values between the mixtures of $\mathrm{Zn}^{2+}$-chemicals with those of $n \mathrm{ZnO}$ chemicals was not significant $(P>0.05)$, not only in acute toxicity test but also in chronic toxicity test. The antagonistic or additive effects for $n \mathrm{ZnO}$-chemicals can be observed in most mixtures, with the TU values ranging from 0.75 to 1.77 and 0.47 to 2.45 in acute toxicity test and chronic test, respectively. We also observed that the prediction accuracy of CA and IA models was not very well in the mixtures where the difference between the toxicity ratios of the components was small (less than about 10), with the mean absolute percentage error (MAPE) values ranging from 0.14 to 0.67 for CA model and 0.17-0.51 for IA model, respectively.

Conclusion: We found that the dissolved $\mathrm{Zn}^{2+}$ mainly accounted for the $\mathrm{nZnO}$ toxicity in the mixtures of $\mathrm{nZnO}$ chemicals, and the joint effects of these mixtures were mostly antagonism and additivity. CA and IA models were unsuitable for predicting the mixture toxicity of $n \mathrm{ZnO}-$ chemicals at their equitoxic ratios.
\end{abstract}

Keywords: Zinc oxide nanoparticle, $\mathrm{Zn}^{2+}$, Mixture toxicity, Vibrio fischeri

\section{Introduction}

The nanoparticles (NPs) have been increasingly manufactured in industry because of the well-known characteristics such as high reactivity, electromagnetic properties and high antibacterial property [1]. Zinc oxide

\footnotetext{
*Correspondence: limi_2014@126.com; zouxming_80@hotmail.com ${ }^{\dagger}$ Fen Chen and Ligui Wu contributed equally to this work

${ }^{1}$ College of Environmental Science and Engineering, Guilin University of Technology, Guilin 541004, China

${ }^{2}$ College of Life Science, Jinggangshan University, Ji'an 343009, China Full list of author information is available at the end of the article
}

nanoparticle $(n \mathrm{ZnO})$, one of the most popular manufactured metal oxide nanomaterials, has unique properties (i.e., surface area and reactive sites) due to the extremely small size and is increasingly used in a range of products, such as sunscreens, cosmetics and antibacterial ointments [2]. The wide applications have caused a rapid increase in the production of $n \mathrm{ZnO}$, with 30,000 tons worldwide in 2010 [3]. As a result, the amount of $n \mathrm{ZnO}$ entering the environment is increasing and the occurrences of $n \mathrm{ZnO}$, in the range $1-10 \mu \mathrm{g} / \mathrm{L}$ or higher, have been commonly reported in natural water and sediments

\section{Springer Open}

(c) The Author(s) 2020. This article is licensed under a Creative Commons Attribution 4.0 International License, which permits use, sharing, adaptation, distribution and reproduction in any medium or format, as long as you give appropriate credit to the original author(s) and the source, provide a link to the Creative Commons licence, and indicate if changes were made. The images or other third party material in this article are included in the article's Creative Commons licence, unless indicated otherwise in a credit line to the material. If material is not included in the article's Creative Commons licence and your intended use is not permitted by statutory regulation or exceeds the permitted use, you will need to obtain permission directly from the copyright holder. To view a copy of this licence, visit http://creativeco mmons.org/licenses/by/4.0/. 
$[4,5]$. Consequently, there is a critical need to investigate the toxic effect and the potential health risk of $n \mathrm{ZnO}$ [6].

To date, the studies of toxic effects for $n \mathrm{ZnO}$ were mostly focused in the field of individual pollution, and the results demonstrated that $n \mathrm{ZnO}$ can produce toxic effect upon bacterial, crustaceans, earthworms and mammalian cells $[7,8]$. Adams et al. [9] determined toxicity of $n \mathrm{ZnO}$, nano-titanium dioxide $\left(n \mathrm{TiO}_{2}\right)$ and nano-silicon dioxide $\left(n \mathrm{SiO}_{2}\right)$ upon the Escherichia coli and found that $n \mathrm{ZnO}$ was the most toxic nanoparticle. Furthermore, some studies were also performed for the purpose of understanding the toxicity mechanism of $n \mathrm{ZnO}$ [10]. $n \mathrm{ZnO}$ can cause damage to the organ and change osmoregulatory of Oreochromis niloticus [11]; the phosphodiester bond of L-R-phosphatidylethanolamine in Escherichia coli can be broken by $n \mathrm{ZnO}$ [12]. Moreover, a variety of studies proved that the toxicity of $n \mathrm{ZnO}$ is related to the dissolution of $\mathrm{Zn}^{2+}$ [13]. For instance, $n \mathrm{ZnO}$ caused the cytotoxicity by means of interfering with the homeostasis of $\mathrm{Zn}^{2+}$ [14]; Zhang et al. [15] proved the toxic difference of various $n \mathrm{ZnO}$ particles mainly depended on their dissolution.

Organisms are typically exposed to multiple mixtures of pollutants rather than single chemicals [16]. In the process of transportation and disposal, it is conceivable that NPs are able to form nanoparticle-toxin complexes due to their high surface area and large aggregates [17]; thus, there are ongoing concerns on evaluating the environmental risk for the mixtures containing NPs. Recently, the toxic effects of $n \mathrm{ZnO}$ combined with other chemicals were investigated in few studies [18]. The joint effects of the $n \mathrm{ZnO}$ and surfactants, for example, were investigated at equitoxic mixtures in acute toxicity test, which showed that the joint effects can be explained by the interactions between the $\mathrm{Zn}^{2+}$ and the surfactants [19]. In the field of toxicology, chemicals are classified as narcotic or reactive compounds based on their mode of action (MOA) for a better mechanistic understanding of interactions in the mixture toxicity [20]. A variety of studies proved that mixtures of compounds exerting only one MOA (narcotic or reactive) can be assumed as additive behavior, whereas the interactions of differently acting compounds tend to yield a less or more mixture toxicity [21]. Unfortunately, the toxic effects of $n \mathrm{ZnO}$ combined with other chemicals were rarely investigated, leading to the fact that in the mixture pollution, it is still unclear whether the dissolved $\mathrm{Zn}^{2+}$ also mainly accounts for the $n \mathrm{ZnO}$ toxicity in the mixtures of $n \mathrm{ZnO}$-chemicals.

In the field of mixture toxicology, the interactions of chemicals always cause the changes in the different joint effects, including synergism, antagonism and additivity [22]. For instance, the joint effects of the $n \mathrm{ZnO}$ and pollutants were investigated in acute toxicity test, and the results showed antagonism [23]; the additive effect between $(n \mathrm{ZnO})$ with nano-copper oxide $(n \mathrm{CuO})$ was identified in the mixture toxic effects upon Scenedesmus obliquus [24]; the antagonistic effect between $n \mathrm{ZnO}$ with $\mathrm{Pb}$ was observed in the mixture toxic effects upon Leucaena leucocephala seedling [25]. However, the joint effects between $n \mathrm{ZnO}$ and chemicals with different MOA have been rarely investigated, and the predictive powers of the concentration addition (CA) and independent action (IA) models have not been verified, although CA and IA models were extensively employed to predict the toxic effects of mixtures [26].

Vibrio fischeri, the marine bacterium, has been widely used as the test organism for investigating the toxicity of pollutants, including $n \mathrm{ZnO}$ [27], antibiotics [26, 28], and heavy metals [29]. In recent years, reactive compounds (i.e., antibiotics) and narcotic compounds (i.e., lignin phenols) were frequently detected in Yangtze River Basin and reported in many previous studies [30, 31]. In addition, researches have suggested that organisms are exposed to the metal NPs and metal ions in the Yangtze River [32, 33]. Therefore, the purpose of this study is to (1) explore the role of $\mathrm{Zn}^{2+}$ in $n \mathrm{ZnO}$ toxicity of the binary mixtures containing $n \mathrm{ZnO}$ and chemicals with different MOA, (2) evaluate the joint effects of $n \mathrm{ZnO}$ and tested chemicals, and (3) investigate the predictive powers of CA and IA models for the mixture toxicities of $n \mathrm{ZnO}$ and tested chemicals.

\section{Materials and methods \\ Test materials}

The freeze-dried marine bacterium, $V$. fischeri, was supplied by the Institute of Soil Science, Chinese Academy of Sciences, Nanjing PRC. $n \mathrm{ZnO}(30 \pm 10 \mathrm{~nm})$, $\mathrm{ZnSO}_{4}\left(\mathrm{Zn}^{2+}\right)$, four narcotic compounds (aniline (AL), 2-nitroaniline (NAL), $p$-toluidine (TD) and hydroquinone (HQ)) and five reactive compounds (sulfamethoxazole (SMZ), sulfapyridine (SPY), sulfadiazine (SD), tetracycline hydrochloride (TTC) and oxytetracycline hydrochloride (OTC)) were purchased from Aladdin Reagent Company (Shanghai, China, www.aladdin-e. com) and were used without further purification. The detailed information of 9 organic chemicals is listed in Additional file 1: Table S1.

\section{Toxicity test \\ Single toxicity test}

The single toxicity test was performed following our previous methods [28]. That is, a $3 \% \mathrm{NaCl}$ solution was used as the diluent and the bioluminescence of $V$. fischeri was recorded over a range of chemical concentrations by a SpectraMax M5 plate reader (Molecular Devices, Sunnyvale, California). The exposure time of 
tested chemicals with $V$. fischeri for acute and chronic toxicity test was $15 \mathrm{~min}$ and $12 \mathrm{~h}$, respectively. The inhibition of the tested chemicals toward bioluminescence was calculated as Eq. 1. Based on the decrease in light emission, the obtained concentration relationship data were fitted using dose-response model (Eq. 2) [34] and reported in unit of $\mathrm{mg} / \mathrm{L}$. The detailed information about single toxicity test is presented in Additional file 1: Fig. S1.

$$
Y=\frac{I_{\text {control }}-I_{s}}{I_{\text {control }}} \times 100 \%
$$

where $Y$ is the inhibition ratio or response, $I_{\text {control }}$ and $I_{\mathrm{s}}$ are the average relative light units of $V$. fischeri exposed to the controls and test chemicals, respectively.

$$
Y=A_{2}+\frac{A_{2}-A_{1}}{1+10^{\left(\log C_{0}-C\right) \times P}}
$$

where $A_{1}$ and $A_{2}$ are bottom inhibition and top inhibition, respectively. $C$ is the concentration of the tested chemical, $C_{0}$ is the value of $C$ at $50 \%$ of the inhibition ratio, and $P$ is the parameter of slope for the concentration-response relationship curve.

\section{Mixture toxicity test}

The binary mixtures, including mixtures at equitoxic ratios and the mixtures at non-equitoxic ratios based on the single toxicity results $\left(\mathrm{EC}_{50}\right)$, were prepared in ratios $\left(1: 10^{2.5}, 1: 10^{2}, 1: 10^{1.5}, 1: 10,1: 10^{0.5}, 1: 1,10^{0.5}: 1,10: 1,10^{1.5}: 1\right.$, $\left.10^{2}: 1,10^{2.5}: 1\right)$ of the individual concentration $(\mathrm{n}(\mathrm{nZnO}$ or $\mathrm{Zn}^{2+}$ ):m (chemicals), $\mathrm{mg} / \mathrm{L}$ ). The binary mixture toxicity tests were conducted in a same method as the analysis of individual toxicity test. Mixture toxicity data were fitted and described as $\mathrm{EC}_{\mathrm{i}, \mathrm{M}}$ (Eq. 3) [35]. The joint effects of the mixtures were represented as the sum of toxic units (TU) [36], as shown in Eq. 4.

$$
\begin{gathered}
E C_{\mathrm{i}, \mathrm{M}}=\frac{C_{\mathrm{A}}+C_{\mathrm{B}}}{\frac{C_{\mathrm{A}}}{\mathrm{E} C_{\mathrm{i}, \mathrm{A}}}+\frac{C_{\mathrm{B}}}{\mathrm{E} C_{\mathrm{i}, \mathrm{B}}}} \\
\mathrm{TU}=\frac{C_{\mathrm{A}}}{E C_{50 \mathrm{~A}}}+\frac{C_{\mathrm{B}}}{\mathrm{E} C_{50 \mathrm{~B}}}
\end{gathered}
$$

where $\mathrm{EC}_{50 \mathrm{~A}}$ and $\mathrm{EC}_{50 \mathrm{~B}}$ are median effective inhibition concentrations of components $\mathrm{A}$ and $\mathrm{B}$, respectively. $\mathrm{EC}_{\mathrm{i}, \mathrm{M}}$ is the effective concentration of the mixtures. $C_{\mathrm{A}}$ and $C_{\mathrm{B}}$ are the concentrations of the individual chemical in mixtures at median inhibition. Simple additivity is characterized by $1.2>\mathrm{TU}>0.8$, while $\mathrm{TU}>1.2$ represents antagonism and $\mathrm{TU}<0.8$ indicates synergism [37].

\section{Toxicity prediction}

Concentration addition (CA) and independent action (IA) are two classical models for mixture toxicity prediction and are widely used to predict the joint effect of mixtures [38]. CA and IA models are expressed mathematically as Eqs. (5) and (6), respectively:

$$
\mathrm{EC}_{\mathrm{x}, \mathrm{m}}=\left(\frac{P_{\mathrm{A}}}{\mathrm{EC}_{\mathrm{x}, \mathrm{A}}}+\frac{P_{\mathrm{B}}}{\mathrm{EC}_{\mathrm{x}, \mathrm{B}}}\right)^{-1},
$$

where $\mathrm{EC}_{\mathrm{x}, \mathrm{m}}$ is the concentration of the mixture eliciting $X \%$ effect, $P_{\mathrm{A}}$ and $P_{\mathrm{B}}$ are the concentration ratios of $\mathrm{A}$ and $\mathrm{B}$ components in the mixture, $\mathrm{EC}_{\mathrm{x}, \mathrm{A}}$ and $\mathrm{EC}_{\mathrm{x}, \mathrm{B}}$ denote the concentrations of the $\mathrm{A}$ and $\mathrm{B}$ components that elicit an $X \%$ effect.

$$
\mathrm{E}\left(\mathrm{c}_{\mathrm{m}}\right)=1-\left(1-E\left(\mathrm{c}_{\mathrm{A}}\right)\right) \times\left(1-E\left(\mathrm{c}_{\mathrm{B}}\right)\right),
$$

where $E\left(C_{m}\right)$ is the toxic effect of mixture, $E\left(C_{A}\right)$ and $E\left(C_{B}\right)$ are the effect from analyte $A$ and $B$ if applied singly at an exposure concentration of $A$ and $B$, respectively.

\section{Statistics}

SPSS 25.0 software (SPSS Inc.) was used to test the significant difference of the results and $P<0.05$ was considered to be statistically significant. The statistic quality of linear models was evaluated by determination coefficients $\left(R^{2}\right)$, the formula as shown Eq. 7 [39]. The parameters of mean absolute percentage error (MAPE) (Eq. 8) and root mean square error (RMSE) (Eq. 9) were applied to measure the prediction accuracy of CA and IA models [40]. These indices were obtained by the following equations:

$$
\mathrm{R}^{2}=\left(\frac{\sum_{i=1}^{n}\left(y_{i}-\bar{y}\right)\left(\hat{y}_{i}-\overline{\hat{y}}\right)}{\sqrt{\sum_{1=1}^{n}\left(y_{i}-\bar{y}\right)^{2} \sum_{i=1}^{n}\left(\hat{y}_{i}-\overline{\hat{y}}\right)^{2}}}\right)^{2},
$$

where $\overline{\hat{y}}$ is the mean predicted responses.

$$
\begin{aligned}
& \text { MAPE }=\frac{1}{M} \sum_{\mathrm{k}=1}^{M}\left|\frac{\hat{p}_{\text {ettc }}(k)-p_{\text {ettc }}(k)}{p_{\text {ettc }}(k)}\right| \times 100 \%, \\
& \text { RMSE }=\sqrt{\frac{1}{M} \sum_{\mathrm{k}=1}^{M}\left[\hat{p}_{\text {ettc }}(k)-p_{\text {ettc }}(k)\right]^{2},}
\end{aligned}
$$

where $M$ is the number of sample intervals.

\section{Results and discussions}

\section{The single toxicity of tested chemicals}

To investigate the mixtures' toxicity of $n \mathrm{ZnO}$ and chemicals with different MOA, the single toxicity of 
$n \mathrm{ZnO}, \mathrm{Zn}^{2+}$ and other 9 chemicals to $V$. fischeri was determined in acute and chronic toxicity test. The data were fitted by the model of dose-response and obtained curves are presented in Fig. 1 . The values of $R^{2}$ suggested a good fitting (0.977-0.999). In the case of acute toxicity (Fig. 1a), $n \mathrm{ZnO}$ and $\mathrm{Zn}^{2+}$ presented higher toxic effects than other tested chemicals, $\mathrm{EC}_{50}$ values for tested chemicals were ranging from $1.17 \mathrm{mg} / \mathrm{L}$ to $319.24 \mathrm{mg} / \mathrm{L}$, and the order of acute toxicity was as follows: $\quad n \mathrm{ZnO}>\mathrm{Zn}^{2+}>\mathrm{HQ}>\mathrm{SMZ}>\mathrm{NAL}>\mathrm{TD}>\mathrm{AL}>$ OTC $>$ TTC $>$ SD $>$ SPY. As far as chronic toxicity test (Fig. 1b), results showed that OTC presented higher toxic effects than other tested chemicals, $\mathrm{EC}_{50}$ values for tested chemicals were ranging from $1.17 \mathrm{E}-2 \mathrm{mg} / \mathrm{L}$ to $100.64 \mathrm{mg} / \mathrm{L}$, and the order of chronic toxicity was as follows: $\mathrm{OTC}>\mathrm{TTC}>\mathrm{HQ}>\mathrm{SMZ}>\mathrm{NAL}>\mathrm{SD}>\mathrm{TD}>n \mathrm{Z}$ $\mathrm{nO}>\mathrm{Zn}^{2+}>\mathrm{SPY}>\mathrm{AL}$.

\section{Mixture toxicity of $\mathrm{nZnO}$ and chemicals with different MOA Acute toxicity test}

Based on the results of the single acute toxicity test, the mixture toxicity of $n \mathrm{ZnO} / \mathrm{Zn}^{2+}$ and 9 tested chemicals with different MOA was determined at their equitoxic ratios (Additional file 1: Fig. S2). As shown in Additional file 1: Fig. S2, the relationship between the luminescent inhibition ratio and the concentration of these mixtures was good, with $R^{2}$ ranging from 0.978 to 0.999 for $n \mathrm{ZnO}-$ chemicals and from 0.982 to 0.993 for $\mathrm{Zn}^{2+}$-chemicals, respectively. The difference between $E C_{50 \mathrm{M}}^{15 \mathrm{~min}}$ for binary mixture containing $n \mathrm{ZnO}$ and $E C_{50 \mathrm{M}}^{15 \mathrm{~min}}$ for binary mixture of $\mathrm{Zn}^{2+}$-chemicals is presented as Fig. 2a. As shown, the difference was not significant for tested chemicals $(P>0.05)$. To further verify the results, the acute mixture toxicity of $n \mathrm{ZnO} / \mathrm{Zn}^{2+}$ combined with SMZ (a reactive compound) and AL (a narcotic compound) was subsequently determined at non-equitoxic ratios (Additional file 1: Fig. S3). Figure 2b indicates that in acute toxicity test, the difference between $E C_{50 \mathrm{M}}^{15 \mathrm{~min}}$ for $n \mathrm{ZnO}-$ $\mathrm{SMZ}$ and $E C_{50 \mathrm{M}}^{15 \mathrm{~min}}$ for $\mathrm{Zn}^{2+}-\mathrm{SMZ}$ was still not significant $(P>0.05)$. Furthermore, the same conclusion can be obtained for $n \mathrm{ZnO}-\mathrm{AL}$ and $\mathrm{Zn}^{2+}-\mathrm{AL}$ at their non-equitoxic ratios $(P>0.05$, Fig. $2 \mathrm{c})$.

\section{Chronic toxicity test}

Based on the results of the single chronic toxicity, the mixture toxicity of $n \mathrm{ZnO} / \mathrm{Zn}^{2+}$ and these chemicals was determined at their equitoxic ratios (Additional file 1: Fig. S4). As shown in Additional file 1: Fig. S4, the relationship between the luminescent inhibition ratio and the concentration of these mixtures was good, with $R^{2}$ ranging from 0.966 to 0.994 for $n \mathrm{ZnO}$-chemicals and from 0.956 to 0.991 for $\mathrm{Zn}^{2+}$-chemicals. In the case of equitoxic ratios for chronic toxicity test, the difference between $E C_{50 \mathrm{M}}^{12 \mathrm{~h}}$ for binary mixtures containing $n \mathrm{ZnO}$ and $E C_{50 \mathrm{M}}^{12 \mathrm{~h}}$ for binary mixtures containing $\mathrm{Zn}^{2+}$ is presented as Fig. $2 \mathrm{~d}$. It can be observed that the difference was still not significant for tested mixtures $(P>0.05)$. To further verify above results, the chronic mixture toxicity of $n \mathrm{ZnO} / \mathrm{Zn}^{2+}$ combined with SMZ (a reactive compound) and AL (a narcotic compound) was determined at their non-equitoxic ratios (Additional file 1: Fig. S5). The results of Fig. 2e, $\mathrm{f}$ consistently indicated that in chronic toxicity test, the difference between $E C_{50 \mathrm{M}}^{12 \mathrm{~h}}$ for binary mixtures of $n \mathrm{ZnO}-$ SMZ/AL with $E C_{50 \mathrm{M}}^{12 \mathrm{~h}}$ for binary mixtures of $\mathrm{Zn}^{2+}-\mathrm{SMZ/}$ $\mathrm{AL}$ at their non-equitoxic ratios was still not significant $(P>0.05)$.

Consequently, dissolved $\mathrm{Zn}^{2+}$ mainly accounted for the $n \mathrm{ZnO}$ toxicity in the mixtures of $n \mathrm{ZnO}$-reactive chemicals and in the mixtures of $n \mathrm{ZnO}$-narcotic chemicals, not only in acute toxicity test but also in chronic toxicity test.
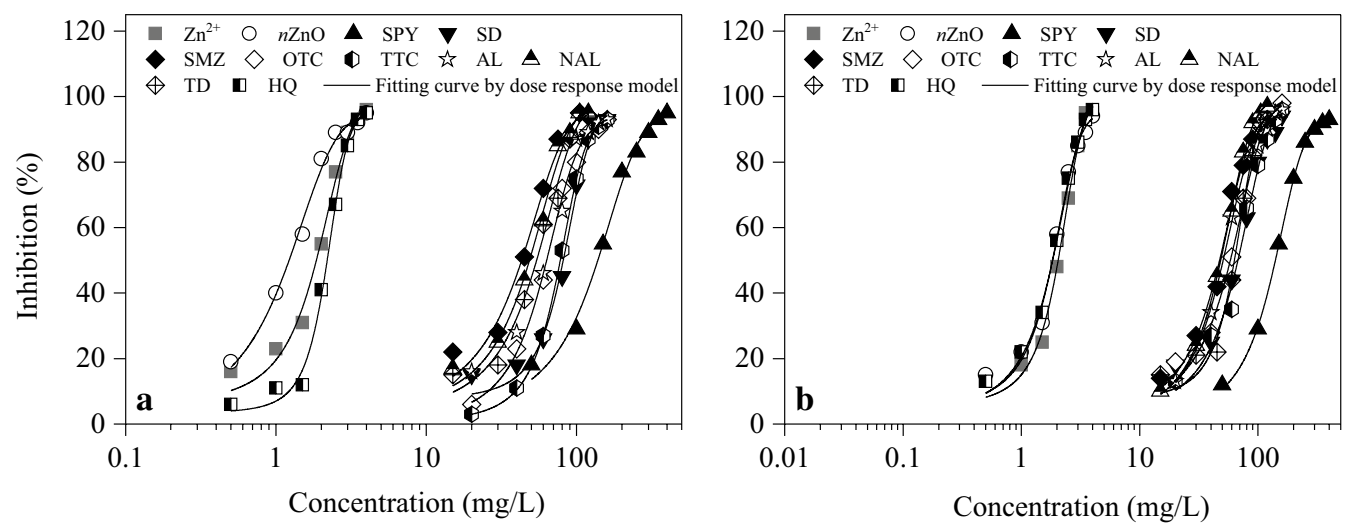

Fig. 1 The single toxic effects of chemicals upon $V$. fischeri and the fitted dose response curves. a The acute toxicity test results, $\mathbf{b}$ the chronic toxicity test results 

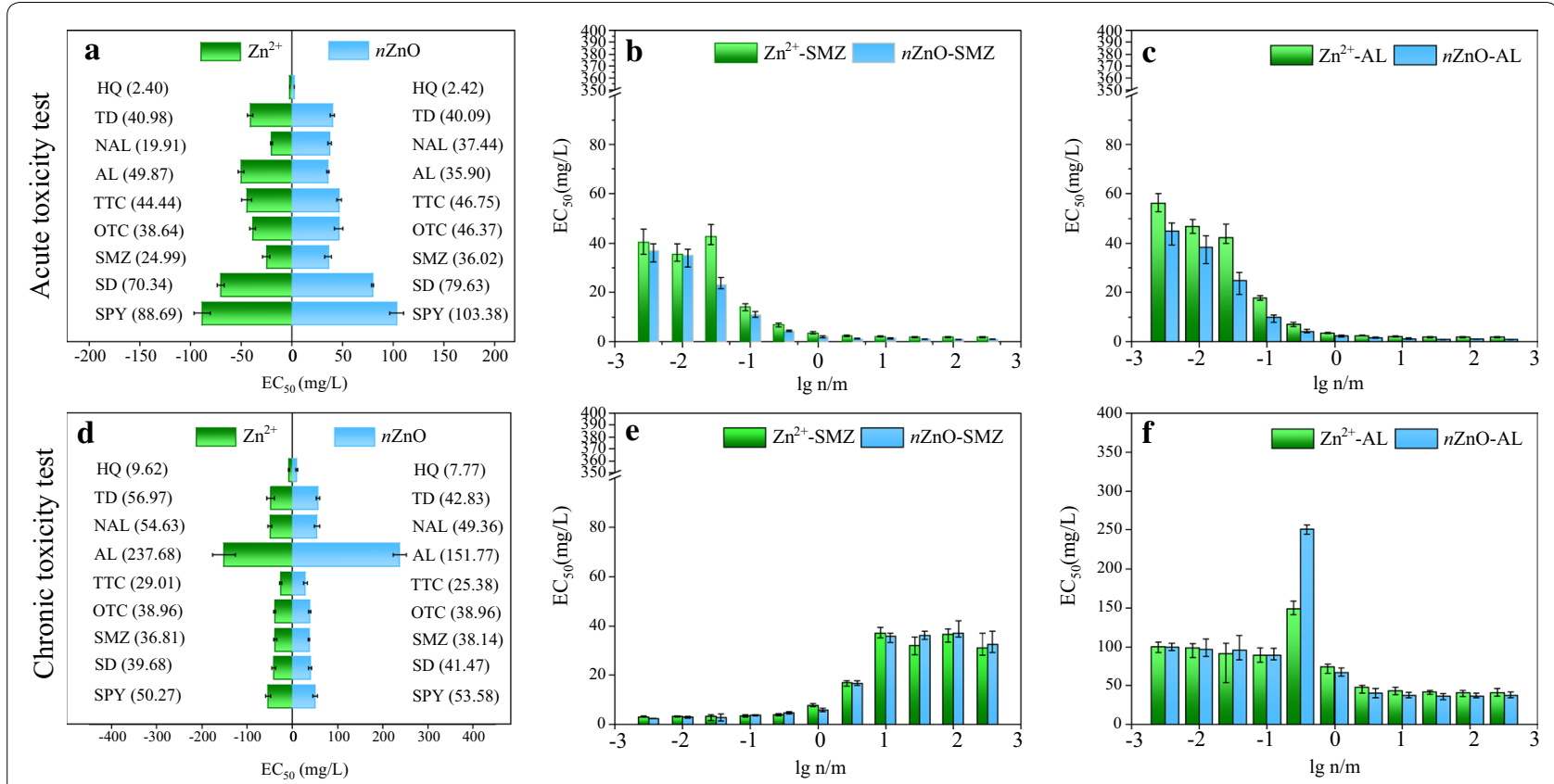

Fig. 2 Comparison of mixture toxicity between $\mathrm{Zn}^{2+}$-chemicals with $n \mathrm{ZnO}$-chemicals. a $\mathrm{Zn}^{2+}$-chemicals and $n \mathrm{ZnO}$-chemicals at equitoxic ratios. $\mathrm{B}$ in acute test, $\mathbf{b} \mathrm{Zn}^{2+}-\mathrm{SMZ}$ and $n \mathrm{ZnO}-\mathrm{SMZ}$ at non-equitoxic ratios in acute test, $\mathbf{c} \mathrm{Zn}^{2+}-\mathrm{AL}$ and $n Z \mathrm{ZnO}-\mathrm{AL}$ at non-equitoxic ratios in acute test, $\mathbf{d}$ $\mathrm{Zn}^{2+}$-chemicals and $n \mathrm{ZnO}$-chemicals at equitoxic ratios in chronic test, $\mathbf{e} \mathrm{Zn}^{2+}-\mathrm{SMZ}$ and $n \mathrm{ZnO}-\mathrm{SMZ}$ at non-equitoxic ratios in chronic test, $\mathbf{f} \mathrm{Zn}^{2+}{ }_{-}$ $\mathrm{AL}$ and $n \mathrm{ZnO}-\mathrm{AL}$ at non-equitoxic ratios in chronic test

\section{Joint effects of $\mathrm{nZnO}$ and chemicals with different MOA}

Based on the mixture toxicity results, the joint effects of mixtures of $n \mathrm{ZnO}$ and tested chemicals were analyzed according to Eq. 3. In the case of acute toxicity test, it can be observed from Fig. 3a that TU values for the mixtures of $n \mathrm{ZnO}$-chemicals at equitoxic ratios ranged from 0.75 to 1.77 . Figure $3 \mathrm{~b}$ shows that $\mathrm{TU}$ values for $n \mathrm{ZnO}-\mathrm{SMZ}$ and $n \mathrm{ZnO}-\mathrm{AL}$ at their non-equitoxic ratios were ranging from 0.93 to 1.25 and from 0.99 to 1.88 , respectively. According to the study of Broderius et al. [37], those results indicated that in acute toxicity test, (1) the joint effects of $n \mathrm{ZnO}$ and chemicals with different MOA were mainly additivity or antagonism, but rarely synergism. For example, the $\mathrm{TU}$ value lower than 0.80 can only be obtained in the mixture of $n \mathrm{ZnO}-\mathrm{NAL}$ and the joint effect was viewed as synergism; and (2) the joint effects for $n \mathrm{ZnO}-\mathrm{SMZ}$ and $n \mathrm{ZnO}-\mathrm{AL}$ were consistent additivity in the acute test at non-equitoxic ratios. In the case of the mixture of $n \mathrm{ZnO}-\mathrm{SMZ}$, for example, the $\mathrm{TU}$ values were $0.86-1.15$.
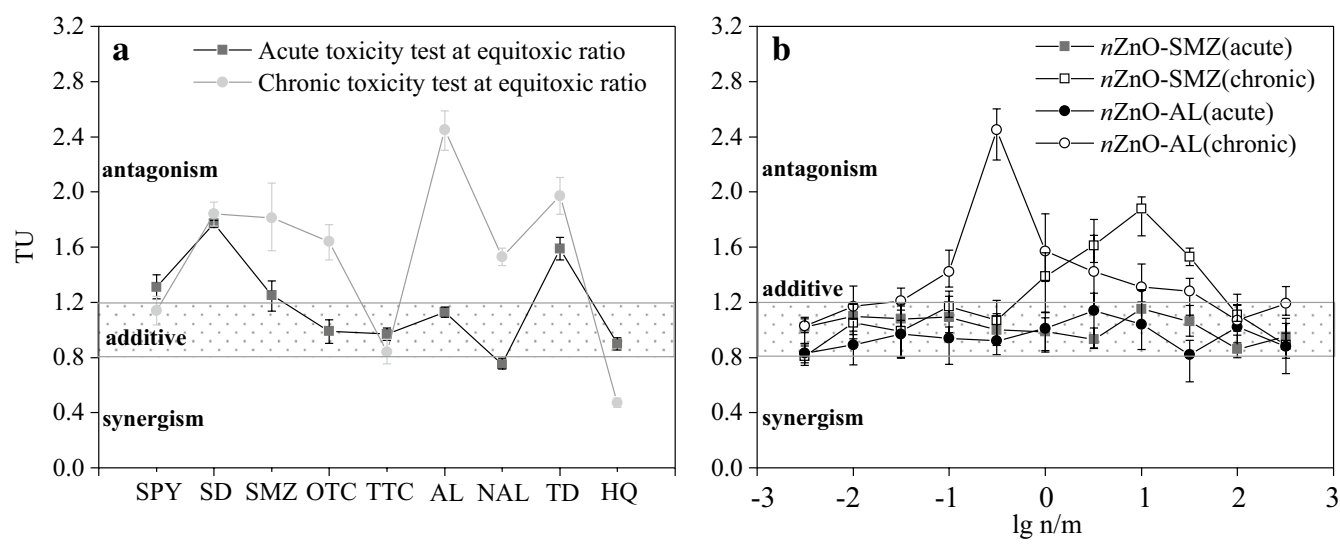

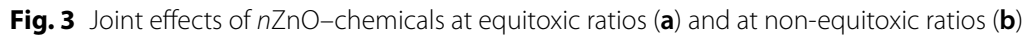


As for chronic toxicity test, it can be observed from Fig. 3a that $\mathrm{TU}$ values for $n \mathrm{ZnO}$ and tested chemicals at equitoxic ratios ranged from 0.47 to 2.45 , indicating the joint effects of $n \mathrm{ZnO}$ and chemicals with different MOA were additivity or antagonism or synergism. The synergism can only be obtained in one mixture $(n \mathrm{ZnO}-\mathrm{HQ})$, and the joint effects for other mixtures were mainly additivity or antagonism. Furthermore, Fig. $3 \mathrm{~b}$ suggests that for the mixtures of $n \mathrm{ZnO}-\mathrm{SMZ}$ and $n \mathrm{ZnO}-\mathrm{AL}$, the joint effects were additivity in the mixtures where the difference between the concentrations of the components is large (e.g., $\lg (\mathrm{n} / \mathrm{m})=-2.5,2,2.5)$, whereas the joint effects were antagonism in the mixtures where the difference between the concentrations of the components is small. In the case of the mixture of $n \mathrm{ZnO}-\mathrm{AL}$, for example, the TU values was 1.57 , the corresponding $\lg \mathrm{n} / \mathrm{m}$ was 0 .

Consequently, it can be concluded that for both acute toxicity test and chronic toxicity test, the joint effects of $n \mathrm{ZnO}$ and chemicals with different MOA were mainly additivity or antagonism. Similar results were obtained for the joint effects of $n \mathrm{ZnO}$ combined with propiconazole by Hackenberger et al. [41]. Zhang et al. [42] also found that the binary joint effects of $\mathrm{Zn}^{2+}$ and 11 nitrosubstituted benzenes to Photobacterium phosphoreum were mainly antagonism.

\section{Mixture toxicity of nZnO-chemicals predicted by CA and IA models}

Based on the mixture toxicity results of $n \mathrm{ZnO}$ and chemicals, the validity and applicability of CA and IA models were further verified (Fig. 4). Results indicated that (1) the prediction accuracy of CA and IA models was satisfied in the mixtures when the difference between the concentrations of the components was large (Fig. 4b, c). When $\lg \mathrm{n} / \mathrm{m}$ was -2.5 or 2.5 for all test mixtures, for example, the values of MAPE and RMSE were mostly ranging from 0.13 to $0.24,0.00302$ to 0.00319 for CA model and were from 0.17 to $0.30,0.00307$ to 0.00340 for IA model, respectively; (2) the prediction accuracy of CA and IA models was poor in the equitoxic mixtures when the joint effects were antagonism or synergism (Fig. 4a). For example, the MAPE values were 1.26 for CA model and 1.97 for IA model in the mixture of $n \mathrm{ZnO}-\mathrm{AL}$ in chronic test; and (3) overall, the prediction accuracy of IA model was better than that of CA model, not only in the mixtures at equitoxic ratios but also in the mixtures at non-equitoxic ratios, as proved by the MAPE values of 0.105 to 2.506 and 0.108 to 2.242 for CA and IA model, respectively. It is well known that CA and IA models were used to predict the toxicity of mixture based on the theoretical assumption that chemicals in the mixture do not interact with each other, therefore both models may underestimate or overestimate the joint effects of binary mixtures [43]. CA model was used by Azevedo et al. [44] to predict the mixture toxicity of $n \mathrm{ZnO}$ and nano-silver $(n \mathrm{Ag})$, the antagonism effect was observed and the mixture toxicity was overestimated. Wang et al. [45] reported the CA model was unsuitable to predict the mixture toxicity of $\mathrm{Zn}^{2+}$ sodium dodecyl benzene sulfonate at equivalent-effect concentration ratio on Vibrio qinghaiensis sp. Q67.

\section{The mixture toxicity mechanism of $\mathrm{nZnO}$ chemicals}

By now, the mixture toxicity of engineered nanomaterials (ENMs) with chemicals is of great interest in the field of toxicology. The mechanisms for the mixture toxicity can
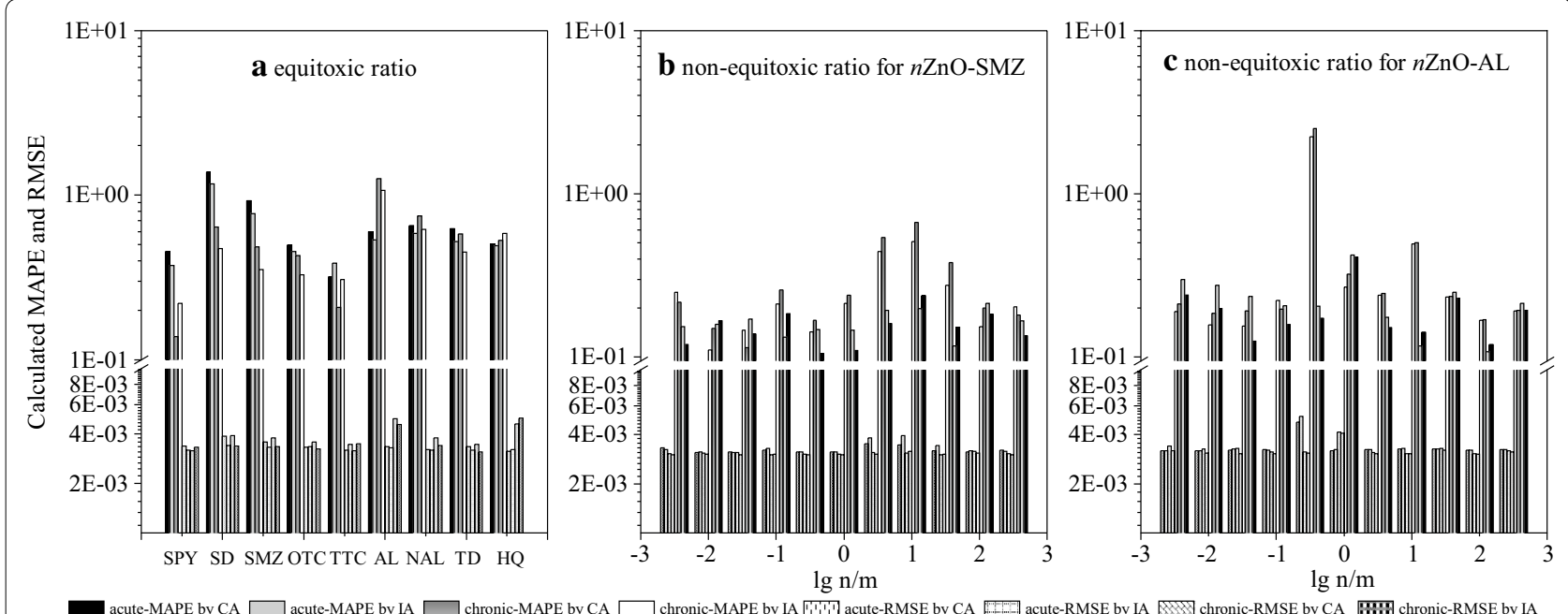

Fig. 4 The results of MAPE and RMSE values for CA and IA models from binary mixtures. a $n Z n O-9$ chemicals at equitoxic ratios, $\mathbf{b} n Z n O-S M Z$ at non-equitoxic ratios, $\mathrm{c} n \mathrm{ZnO}-\mathrm{AL}$ at non-equitoxic ratios 
be mainly classified into the following types (Fig. 5): (1) ENMs effectively affect bioavailability of pollutants either positively or negatively by adsorption, complexation and degradation [46]; (2) the toxicokinetics of pollutants, including the process of uptake, biotransformation, distribution and elimination of pollutants in test organism, can be affected by ENMs by modifying the structure and function of cellular membrane, changing the metabolism pathways and altering the chemical species of pollutants [47]; and (3) ENMs influence the toxicodynamics of pollutants by interfering with the interactions of a toxicant with a biological target and its biological effects [48]. For example, ENMs may ease the entering and transport of pollutants in organisms via "Trojan horse effect" [49], because of the high surface to volume ratio [50]; Carbon nanotubes enter cells through damaging the cell membrane, which subsequently facilitated the entry of pollutants and induced a synergistic toxicity [51]; De La Torre-Roche et al. [52] indicated the dissolved $\mathrm{Ag}^{+}$ from silver nanoparticles (AgNPs) inhibited the activity of aquaporin and decreased the uptake of $p, p^{\prime}-\mathrm{DDE}$, and therefore, reducing the bioaccumulation of $p, p^{\prime}$-DDE in test organisms.

In the case of single toxicity, studies proved that the released $\mathrm{Zn}^{2+}$ mainly accounted for the $n \mathrm{ZnO}$ toxicity upon V. fischeri and Escherichia coli, respectively [27, 53]. In the field of mixture toxicity, the role of released $\mathrm{Zn}^{2+}$ in $n \mathrm{ZnO}$ toxicity remains controversial. The work of $\mathrm{Yi}$ et al. [54], for example, indicated no significant difference between the toxicity of $n \mathrm{ZnO}$-triphenyltin and $\mathrm{Zn}^{2+}$-triphenyltin to Tigriopus japonicas. While
Lakshmi Prasanna et al. [55] reported that the surface defects of $n \mathrm{ZnO}$ induced antibacterial activity via reactive oxygen species generation rather than by dissolved $\mathrm{Zn}^{2+}$. The possible reason for the above difference can be concluded as following: the main toxicity mechanism of $n \mathrm{ZnO}$ may be different for the divergence of exposure condition, because the species of dissolved zinc ion could be changed by the components in the nature [56].

In the present study, the difference of the joint effects between $n \mathrm{ZnO}$-chemicals and $\mathrm{Zn}^{2+}$-chemicals was not significant $(P>0.05)$, not only in acute toxicity test but also in chronic toxicity test, suggesting that the toxicity of $n \mathrm{ZnO}$ on $V$. fischeri was due mainly to the dissolved $\mathrm{Zn}^{2+}$. Thus, the joint effects of the $n \mathrm{ZnO}$ and tested chemicals can be explained by the interactions between the dissolved $\mathrm{Zn}^{2+}$ and these chemicals. The joint effects of tested mixtures were mainly antagonism and additivity (Fig. 3a). The possible reasons for the antagonistic effect can be explained as follows: first, metal ions interact with organic compounds which reduce the effective dose of the pollutants in organism. In case of antibiotics, interactions between metal ions and the functional groups of antibiotics are the main mechanism for decreasing the mixture toxicity [57]. The work of Kim et al. [58], for example, revealed that the complexation reactions between $\mathrm{Cu}^{2+}$ and the phenolic compounds (narcotic compounds) played an important role in reduction of the $\mathrm{Cu}^{2+}$ concentrations and therefore decreased toxicity of the binary mixtures. Second, the components of a binary mixture may compete for binding sites [59]. Hackenberger et al. [41] found that two compounds in the

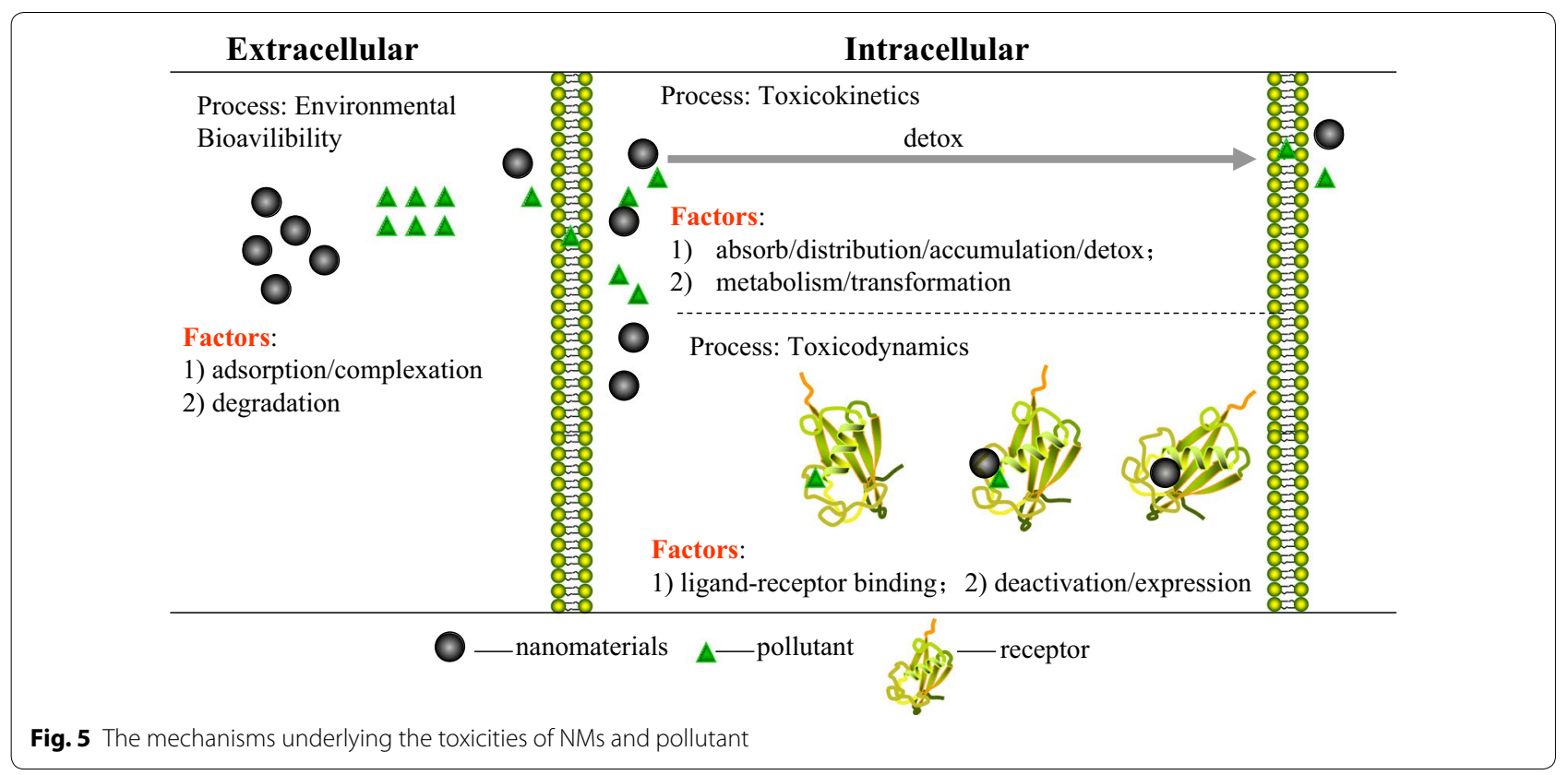


treatment canceled the effect of one another in the mixtures of $n \mathrm{ZnO}$-propiconazole and $\mathrm{Zn}^{2+}$-propiconazole. The only synergism effect on $V$. fischeri occurred in the $n \mathrm{ZnO}-\mathrm{HQ}$ binary experiment. It was well known that phenols can cause damage to cell membrane [60]. Consequently, we speculated that the HQ disrupted the cell membrane integrity of $V$. fischeri, which facilitated the entry of released $\mathrm{Zn}^{2+}$ and increased the mixture toxicity.

\section{Conclusions}

Our results indicated that no significant difference of the toxicity between $n \mathrm{ZnO}$ and $\mathrm{Zn}^{2+}$ was observed not only in single-component system but also in mixture systems of $n \mathrm{ZnO} / \mathrm{Zn}^{2+}$ and chemicals with different MOA, suggesting that $n \mathrm{ZnO}$ toxicity was mainly caused by released $\mathrm{Zn}^{2+}$. Furthermore, the joint effects of $n \mathrm{ZnO}$ and chemicals at equitoxic ratios were mainly antagonism and additivity, while the joint effects of $n \mathrm{ZnO}-\mathrm{SMZ}$ or $n \mathrm{ZnO}-\mathrm{AL}$ were additivity at non-equitoxic ratios. Moreover, the prediction accuracy of CA and IA models was not very well in binary mixtures at equitoxic ratios.

\section{Supplementary information}

Supplementary information accompanies this paper at https://doi. org/10.1186/s12302-020-00320-x.

Additional file 1: Table S1. Detail information of test chemicals. Fig. S1. The setting of test groups in 96-well microplate. Fig. S2. Comparison of dose response curves in acute toxicity test at equitoxic ratios derived from determined data and predicted data by CA and IA models. (a1-a9) nZnO-chemicals, (b1-b9) $\mathrm{Zn}^{2+}$-chemicals, Obs stands for observation. Fig. S3. Comparison of dose response curves in acute toxicity test at non-equitoxic ratios derived from determined data and predicted data by CA and IA models. (a1-a11) nZnO-SMZ, (b1-b11) nZnO-AL, Obs stands for observation. Fig. S4. Comparison of dose response curves in chronic toxicity test at equitoxic ratios derived from determined data and predicted data by CA and IA models. (a1-a9) nZnO-chemicals, (b1-b9) $\mathrm{Zn}^{2+}$-chemicals, Obs stands for observation. Fig. S5. Comparison of dose response curves in chronic toxicity test at non-equitoxic ratios derived from determined data and predicted data by CA and IA models. (a1-a11) nZnO-SMZ, (b1-b11) nZnO-AL, Obs stands for observation.

\section{Abbreviations}

nZnO: Zinc oxide nanoparticle; V. fischeri: Vibrio fischeri; AL: Aniline; NAL: 2-Nitroaniline; TD: $p$-Toluidine; HQ: Hydroquinone; SMZ: Sulfamethoxazole; SPY: Sulfapyridine; SD: Sulfadiazine; TTC: Tetracycline hydrochloride; OTC: Oxytetracycline hydrochloride; CA: Concentration addition; IA: Independent action; TU: Toxic units; MAPE: Mean absolute percentage error; RMSE: Root mean square error; MOA: Mode of action; ENMs: Engineered nanomaterials.

\section{Acknowledgements}

Not applicable.

\section{Authors' contributions}

Conceptualization: XZ, LR and ML. Methodology: XZ, LW. Toxicity test: LW, FC, $X X$ and LR. Data curation: XZ, LW and ML. Writing: XZ and LW. All authors read and approved the final manuscript.

\section{Funding}

The National Natural Science Foundation of China project 31760165, 41461094 Xiaoming Zou; the Outstanding Scholarship of Jiangxi Scientific
Committee 20192BCBL23014 Xiaoming Zou; the Natural Science Foundation of Jiangxi Province 20181BAB203023 Xiaoming Zou; the Educational Commission of Jiangxi Province GJJ160727 Xiaoming Zou.

\section{Availability of data and materials}

All data generated or analyzed during this study are included in this published article (and in Additional file: 1).

\section{Ethics approval and consent to participate}

Not applicable.

\section{Consent for publication}

Not applicable.

\section{Competing interests}

The authors declare that they have no competing interests.

\section{Author details}

${ }^{1}$ College of Environmental Science and Engineering, Guilin University of Technology, Guilin 541004, China. ${ }^{2}$ College of Life Science, Jinggangshan University, Ji'an 343009, China. ${ }^{3}$ College of Urban and Environmental Sciences, Northwest University, Xi'an 710127, China. ${ }^{4}$ College of Environmental Science and Engineering, Tongji University, Shanghai 200092, China.

Received: 31 December 2019 Accepted: 2 March 2020

Published online: 11 March 2020

\section{References}

1. Chen Y, Guo X, Feng J et al (2019) Impact of ZnO nanoparticles on the antibiotic resistance genes (ARGs) in estuarine water: ARG variations and their association with the microbial community. Environ Sci Nano. https ://doi.org/10.1039/C9EN00338J

2. Alipour N, Namazi H (2020) Chelating ZnO-dopamine on the surface of graphene oxide and its application as pH-responsive and antibacterial nanohybrid delivery agent for doxorubicin. Mater Sci Eng C 108:110459. https://doi.org/10.1016/j.msec.2019.110459

3. Keller AA, McFerran S, Lazareva A et al (2013) Global life cycle releases of engineered nanomaterials. J Nanopart Res 15(6):1692. https://doi. org/10.1007/s11051-013-1692-4

4. Chen X, O'Halloran J, Jansen MAK (2016) The toxicity of zinc oxide NPs to Lemna minor (L.) is predominantly caused by dissolved Zn. Aquat Toxicol 174:46-53. https://doi.org/10.1016/j.aquatox.2016.02.012

5. Majedi SM, Lee HK, Kelly BC (2012) Chemometric analytical approach for the cloud point extraction and inductively coupled plasma mass spectrometric determination of zinc oxide NPs in water samples. Anal Chem 84(15):6546-6552. https://doi.org/10.1021/ac300833t

6. Wang D, Lin Z, Wang T et al (2016) Where does the toxicity of metal oxide NPs come from: the NPs, the ions, or a combination of both? J Hazard Mater 308:328-334. https://doi.org/10.1016/j.jhazmat.2016.01.066

7. Xiao Y, Vijver MG, Chen G et al (2015) Toxicity and accumulation of Cu and ZnO NPs in Daphnia magna. Environ Sci Technol 49(7):4657-4664. https ://doi.org/10.1021/acs.est.5b00538

8. Hund-Rinke K, Schlich K, Klawonn T (2012) Influence of application techniques on the ecotoxicological effects of nanomaterials in soil. Environ Sci Eur. 24:30. https://doi.org/10.1186/2190-4715-24-30

9. Adams LK, Lyon DY, Alvarez PJJ (2006) Comparative eco-toxicity of nanoscale $\mathrm{TiO}_{2}, \mathrm{SiO}_{2}$, and $\mathrm{ZnO}$ water suspensions. Water Res 40(19):35273532. https://doi.org/10.1016/j.watres.2006.08.004

10. Bacchetta R, Santo N, Marelli M et al (2017) Chronic toxicity effects of $\mathrm{ZnSO}_{4}$ and $\mathrm{ZnO}$ NPs in Daphnia magna. Environ Res 152:128-140. https:// doi.org/10.1016/j.envres.2016.10.006

11. Kaya H, Aydın F, Gürkan M et al (2016) A comparative toxicity study between small and large size zinc oxide NPs in tilapia (Oreochromis niloticus): organ pathologies, osmoregulatory responses and immunological parameters. Chemosphere 144:571-582. https://doi.org/10.1016/j.chemo sphere.2015.09.024

12. Jiang W, Yang K, Vachet RW et al (2010) Interaction between oxide nanoparticles and biomolecules of the bacterial cell envelope as examined 
by infrared spectroscopy. Langmuir 26(23):18071-18077. https://doi. org/10.1021/la103738e

13. Zhang C, Wang J, Tan $L$ et al (2016) Toxic effects of nano-ZnO on marine microalgae Skeletonema costatum: attention to the accumulation of intracellular Zn. Aquat Toxicol 178:158-164. https://doi.org/10.1016/j.aquat ox.2016.07.020

14. Kao YY, Chen YC, Cheng TJ et al (2012) Zinc oxide nanoparticles interfere with zinc ion homeostasis to cause cytotoxicity. Toxicol Sci 125:462-472. https://doi.org/10.1093/toxsci/kfr319

15. Zhang J, Song W, Guo J et al (2012) Toxic effect of different ZnO particles on mouse alveolar macrophages. J Hazard Mater 219:148-155. https:// doi.org/10.1016/j.jhazmat.2012.03.069

16. Uwizeyimana H, Wang M, Chen W et al (2017) The eco-toxic effects of pesticide and heavy metal mixtures towards earthworms in soil. Environ Toxicol Pharmacol 55:20-29. https://doi.org/10.1016/j.etap.2017.08.001

17. Zhu X, Zhou J, Cai Z (2011) $\mathrm{TiO}_{2}$ nanoparticles in the marine environment: impact on the toxicity of tributyltin to abalone (Haliotis diversicolor supertexta) embryos. Environ Sci Technol 45(8):3753-3758. https://doi. org/10.1021/es103779h

18. Liu Y, Nie Y, Wang J et al (2018) Mechanisms involved in the impact of engineered nanomaterials on the joint toxicity with environmental pollutants. Ecotoxicol Environ Saf 162:92-102. https://doi.org/10.1016/j. ecoenv.2018.06.079

19. Wang D, Lin Z, Yao Z et al (2014) Surfactants present complex joint effects on the toxicities of metal oxide nanoparticles. Chemosphere 108:70-75. https://doi.org/10.1016/j.chemosphere.2014.03.010

20. Escher BI, Hermens JLM (2002) Modes of action in ecotoxicology: their role in body burdens, species sensitivity, QSARs, and mixture effects, Environ Sci Technol 36:4201-4217. https://doi.org/10.1021/es015848h

21. Spurgeon DJ, Jones OAH, Dorne JL et al (2010) Systems toxicology approaches for understanding the joint effects of environmental chemical mixtures. Sci Total Environ 408:3725-3734. https://doi.org/10.1016/j. scitotenv.2010.02.038

22. Altenburger R, Nendza M, Schüürmann G (2003) Mixture toxicity and its modeling by quantitative structure-activity relationships. Environ Toxicol Chem 22:1900-1915. https://doi.org/10.1897/01-386

23. Wang D, Gao Y, Lin Z, Yao Z, Zhang W (2014) The joint effects on Photobacterium phosphoreum of metal oxide nanoparticles and their most likely coexisting chemicals in the environment. Aquat Toxicol 154:200206. https://doi.org/10.1016/j.aquatox.2014.05.023

24. Ye N, Wang Z, Fang H et al (2017) Combined ecotoxicity of binary zinc oxide and copper oxide nanoparticles to Scenedesmus obliquus. Environ Lett 52:555-560. https://doi.org/10.1080/10934529.2017.1284434

25. Venkatachalam P, Jayaraj M, Manikandan R et al (2016) Zinc oxide nanoparticles (ZnO NPs) alleviate heavy metal-induced toxicity in Leucaena leucocephala seedlings: a physiochemical analysis. Plant Physiol Biochem 110:59. https://doi.org/10.1016/j.plaphy.2016.08.022

26. Zou X, Xiao X, Yu H et al (2017) Hormetic effects of metal ions upon V. fischeri and the application of a new parameter for the quantitative assessment of hormesis. J Hazard Mater 322:454-460. https://doi.org/10.1016/j. jhazmat.2016.09.045

27. Heinlaan M, Ivask A, Blinova I et al (2008) Toxicity of nanosized and bulk $\mathrm{ZnO}, \mathrm{CuO}$ and $\mathrm{TiO}_{2}$ to bacteria Vibrio fischeri and crustaceans Daphnia magna and Thamnocephalus platyurus. Chemosphere 71:1308-1316. https://doi.org/10.1016/j.chemosphere.2007.11.047

28. Zou X, Lin Z, Deng Z et al (2012) The joint effects of sulfonamides and their potentiator on Photobacterium phosphoreum: differences between the acute and chronic mixture toxicity mechanisms. Chemosphere 86:30-35. https://doi.org/10.1016/j.chemosphere.2011.08.046

29. Tsiridis V, Petala M, Samaras P et al (2006) Interactive toxic effects of heavy metals and humic acids on Vibrio fischeri. Ecotoxicol Environ Saf 63:158-167. https://doi.org/10.1016/j.ecoenv.2005.04.005

30. Li L, Liu D, Zhang Q et al (2019) Occurrence and ecological risk assessment of selected antibiotics in the freshwater lakes along the middle and lower reaches of Yangtze River Basin. J Environ Manage 249:109396. https ://doi.org/10.1016/j.jenvman.2019.109396

31. Zhang K, He D, Cui X et al (2019) Impact of anthropogenic organic matter on the distribution patterns of sediment microbial community from the Yangtze River, China. Geomicrobiol J 36(10):881-893. https://doi. org/10.1080/01490451.2019.1641772
32. Wu S, Zhang S, Gong Y et al (2020) Identification and quantification of titanium nanoparticles in surface water: a case study in Lake Taihu, China. J Hazard Mater 382:121045. https://doi.org/10.1016/j.jhazmat.2019.12104 5

33. He Z, Li F, Dominech S et al (2019) Heavy metals of surface sediments in the Changjiang (Yangtze River) Estuary: distribution, speciation and environmental risks. J Geochem Explor 198:18-28. https://doi.org/10.1016/j. gexplo.2018.12.015

34. Zou X, Xiao X, Zhou H et al (2018) 2018 Effects of soil acidification on the toxicity of organophosphorus pesticide on Eisenia fetida and its mechanism. J Hazard Mater 359:365-372. https://doi.org/10.1016/j.jhazm at.2018.04.036

35. Backhaus T, Altenburger R, Boedeker W et al (2000) Predictability of the toxicity of a multiple mixture of dissimilarly acting chemicals to Vibrio fischeri. Environ Toxicol Chem 19(9):2348-2356. https://doi.org/10.1002/ etc.5620190927

36. Xu S, Nirmalakhandan N (1998) Use of QSAR models in predicting joint effects in multi-component mixtures of organic chemicals. Water Res 32(8):2391-2399. https://doi.org/10.1016/S0043-1354(98)00006-2

37. Broderius SJ, Kahl MD, Hoglund MD (1995) Use of joint toxic response to define the primary mode of toxic action for diverse industrial organic chemicals. Environ Toxicol Chem 14:1591-1605. https://doi.org/10.1002/ etc. 5620140920

38. Backhaus T, Arrhenius Blanck H (2004) Toxicity of a mixture of dissimilarly acting substances to natural algal communities: predictive power and limitations of independent action and concentration addition. Environ Sci Technol 38:6363-6370. https://doi.org/10.1021/es0497678

39. Renaud O, Victoria-Feser MP (2010) A robust coefficient of determination for regression. J Stat Plan Inference 140(7):1852-1862. https://doi. org/10.1016/j.jspi.2010.01.008

40. Jin S, Wang D, Xu C et al (2013) Short-term traffic safety forecasting using Gaussian mixture model and Kalman filter. J Zhejiang Univ Sci A. 14(4):231-243

41. Hackenberger DK, Stjepanović N, Lončarić Ž et al (2019) Effects of single and combined exposure to nano and bulk zinc-oxide and propiconazole on Enchytraeus albidus. Chemosphere 224:572. https://doi.org/10.1016/j. chemosphere

42. Zhang S, Su L, Zhang X et al (2019) Combined Toxicity of nitro-substituted benzenes and Zinc to Photobacterium phosphoreum: evaluation and QSAR analysis. Int J Environ Res Public Health. 16(6):1041. https://doi. org/10.3390/ijerph16061041

43. Cedergreen N, Christensen AM, Kamper A et al (2008) A review of independent action compared to concentration addition as reference models for mixtures of compounds with different molecular target sites. Environ Toxicol Chem 27(7):1621-1632. https://doi.org/10.1897/07-474.1

44. Azevedo SL, Holz T, Rodrigues J et al (2017) A mixture toxicity approach to predict the toxicity of $\mathrm{Ag}$ decorated $\mathrm{ZnO}$ nanomaterials. Sci Total Environ 579:337-344. https://doi.org/10.1016/j.scitotenv.2016.11.095

45. Wang N, Wang XC, Ma X (2015) Characteristics of concentration-inhibition curves of individual chemicals and applicability of the concentration addition model for mixture toxicity prediction. Ecotoxicol Environ Saf 113:176-182. https://doi.org/10.1016/j.ecoenv.2014.12.008

46. Fang Q, Shi Q, Guo Y et al (2016) Enhanced bioconcentration of bisphenol $\mathrm{A}$ in the presence of nano- $\mathrm{TiO}_{2}$ can lead to adverse reproductive outcomes in zebrafish. Environ Sci Technol 50(2):1005-1013. https://doi. org/10.1021/acs.est.5b05024

47. Hu X, Kang J, Lu K et al (2014) Graphene oxide amplifies the phytotoxicity of arsenic in wheat. Sci Rep 4:6122. https://doi.org/10.1038/srep06122

48. Dhasmana A, Jamal QMS, Mir SS et al (2014) Titanium dioxide nanoparticles as guardian against environmental carcinogen benzo [alpha] pyrene. PLOS ONE 9(9):e107068. https://doi.org/10.1371/journal.pone.0107068

49. Limbach LK, Wick P, Manser $P$ et al (2007) Exposure of engineered nanoparticles to human lung epithelial cells: influence of chemical composition and catalytic activity on oxidative stress. Environ Sci Technol 41(11):4158-4163. https://doi.org/10.1021/es062629t

50. Essalhi M, Khet M (2014) Self-sustained webs of polyvinylidene fluoride electrospun nano-fibers: effects of polymer concentration and desalination by direct contact membrane distillation. J Membr Sci 454:133-143. https://doi.org/10.1016/j.memsci.2013.11.056

51. Wang F, Yao J, Liu H et al (2015) Cu and Cr enhanced the effect of various carbon nanotubes on microbial communities in an aquatic 
environment. J Hazard Mater 292:137-145. https://doi.org/10.1016/j. jhazmat.2015.03.032

52. De La Torre-Roche R, Hawthorne J, Musante C et al (2013) Impact of Ag nanoparticle exposure on $p, p^{\prime}$-DDE bioaccumulation by Cucurbita pepo (Zucchini) and Glycine max (Soybean). Environ Sci Technol 47(2):718-725. https://doi.org/10.1021/es3041829

53. Ivask $\mathrm{A}$, Bondarenko $\mathrm{O}$, Jepihhina $\mathrm{N}$ et al (2010) Profiling of the reactive oxygen species-related ecotoxicity of $\mathrm{CuO}, \mathrm{ZnO}, \mathrm{TiO}_{2}$, silver and fullerene nanoparticles using a set of recombinant luminescent Escherichia coli strains: differentiating the impact of particles and solubilised metals. Anal Bioanal Chem 398(2):701-716. https://doi.org/10.1007/s0021 6-010-3962-7

54. Yi X, Zhang K, Han G et al (2018) Toxic effect of triphenyltin in the presence of nano zinc oxide to marine copepod Tigriopus japonicus. Environ Pollut 243:687-692. https://doi.org/10.1016/j.envpol.2018.09.038

55. Lakshmi Prasanna V, Vijayaraghavan R (2015) Insight into the mechanism of antibacterial activity of $\mathrm{ZnO}$ : surface defects mediated reactive oxygen species even in the dark. Langmuir 31(33):9155-9162. https://doi. org/10.1021/acs.langmuir.5b02266

56. Tang Y, Li S, Lu Y et al (2015) The influence of humic acid on the toxicity of nano- $\mathrm{ZnO}$ and $\mathrm{Zn}^{2+}$ to the Anabaena sp. Environ Toxicol 30(8):895-903. https://doi.org/10.1002/tox.21964
57. Turel I (2002) The interactions of metal ions with quinolone antibacterial agents. Coord Chem Rev 232(1-2):27-47. https://doi.org/10.1016/50010 -8545(02)00027-9

58. Kim KT, Lee YG, Kim SD (2006) Combined toxicity of copper and phenol derivatives to Daphnia magna: effect of complexation reaction. Environ Int 32(4):487-492. https://doi.org/10.1016/j.envint.2005.11.002

59. Kinniburgh DG, van Riemsdijk WH, Koopal LK et al (1999) lon binding to natural organic matter: competition, heterogeneity, stoichiometry and thermodynamic consistency. Colloids Surf A 151(1-2):147-166. https:// doi.org/10.1016/S0927-7757(98)00637-2

60. Ma W, Han Y, Xu C et al (2018) Biotoxicity assessment and toxicity mechanism on coal gasification wastewater (CGW): a comparative analysis of effluent from different treatment processes. Sci Total Environ 637:1-8. https://doi.org/10.1016/j.scitotenv.2018.04.404

\section{Publisher's Note}

Springer Nature remains neutral with regard to jurisdictional claims in published maps and institutional affiliations.

\section{Submit your manuscript to a SpringerOpen ${ }^{\odot}$ journal and benefit from:}

- Convenient online submission

- Rigorous peer review

- Open access: articles freely available online

- High visibility within the field

- Retaining the copyright to your article

Submit your next manuscript at $\mathbf{s p r i n g e r o p e n . c o m ~}$ 